\title{
PENINGGIAN SALURAN AIR SEBAGAI SOLUSI MENGURANGI BANJIR DI PERUMAHAN BUKIT KENCANA, BEKASI, JAWA BARAT
}

\author{
Yuli Supodo', Bakti Toni Endaryono², Sony Yudha Perkasa ${ }^{3}$ \\ ${ }^{1}$ Prodi Akuntansi, Universitas Surapati Jakarta \\ 2,3 Prodi Ekonomi Syariah, IAI-N Laa Roiba Bogor \\ *Email: supodo@surapati.ac.id
}

\begin{tabular}{|c|c|}
\hline Informasi Artikel & Abstrak \\
\hline $\begin{array}{l}\text { Kata kunci: } \\
\text { saluran air, solusi, } \\
\text { mengurangi banjir }\end{array}$ & $\begin{array}{l}\text { Kegiatan pengabdian kepada masyarakat berupa pekerjaan peninggian } \\
\text { saluran air di lokasi RT.08-RW.11 Perumahan Bukit Kencana yang lakukan } \\
\text { diharapkan dapat menjadi solusi mengurangi sekaligus mencegah } \\
\text { terjadinya banjir seperti pada saat curah hujan pada awal tahun baru } 2020 \text {. }\end{array}$ \\
\hline $\begin{array}{l}\text { Diterima: } 18-01-2021 \\
\text { Disetujui: 24-01-2021 } \\
\text { Dipubikasikan: } 26-01- \\
2021\end{array}$ & $\begin{array}{l}\text { Metode kegiatan pengabdian masyarakat ini adalah dengan menggunakan } \\
\text { metode PAR (Participatory Action Research) dimana metode ini langsung } \\
\text { pendekatan kepada masyarakat dengan melihat kondisi langsung } \\
\text { dilapangan yang dilaksanakan secara partisipatif di masyarakat. Hasil dari } \\
\text { kegiatan pengabdian masyarakat ini adalah sebelum dilakukan kegiatan } \\
\text { pengabdian masyarakat ini maka warga di perumahan bukit kencana } \\
\text { mengalami banjir dengan ketinggian } 15 \text { hingga } 70 \mathrm{~cm} \text { yang ada didalam } \\
\text { rumah, sehingga kegiatan yang dilakukan adalah peninggian dan pelebaran } \\
\text { saluran air, sehingga mengurangi sekaligus mencegah terjadinya kembali } \\
\text { bencana banjir yang mengakibatkan korban jiwa dan kehilangan harta } \\
\text { benda. }\end{array}$ \\
\hline
\end{tabular}


Peninggian Saluran Air Sebagai Solusi Mengurangi Banjir Di Perumahan Bukit Kencana, Bekasi, Jawa Barat

\section{PENDAHULUAN}

Berbagai aktivitas manusia dan pembangunan yang berkembang pesat, mengakibatkan semakin meningkatnya kebutuhan terhadap lahan. Pengembangan rumah merupakan suatu kebutuhan dari setiap penghuni kawasan perumahan sejalan penambalnn jumlah anggota keluarga atau untuk kebutuhan lain (Setiabudi, 2009).

Banjir merupakan suatu kondisi di mana terjadi luapan air yang berlebih yang mengakibatkan terendamnya suatu. Banjir disini adalah air dalam volume besar dan menggenangi rumah. Banjir juga di sini dapat dikatakan sebagai aliran air yang tidak dapat tertampung lagi oleh, aliran air, kali dan saluran irigasi yang lainnya, air banjir merupakan air yang berasal dari hujan lebat yang terus menerus sehingga dapat menyebabkan luapan sungai. Saat bencana ini terjadi, banyak orang kehilangan harta benda mereka, bahkan dapat menimbulkan korban jiwa. Karena hal tersebut, sudah sepatutnya kita sebagai manusia menjaga alam agar tidak ada lagi terjadinya banjir yang akan merugikan banyak orang. Banjir Pasang Air laut (rob) adalah pola fluktuasi muka air laut yang dipengaruhi oleh gaya tarik benda-benda angkasa, terutama oleh Bulan dan Matahari terhadap massa air laut di Bumi. (Desmawan \& Sukamdi, 2012)

Penyebab banjir yang sering kita tidak sadari adalah kebiasaan akan membuang sampah sembarangan. Sampah yang dibuang sembarangan contohnya di kali, akan dapat mengakibatkan mampetnya aliran air dan akibatnya air kali akan meluap. Hal tersebut menjadi sebuah pemicu terjadinya banjir yang dapat merugikan masyarakat ataupun menimbulkan kerugian harta benda ataupun korban jiwa.

Kurang tertatanya pemukiman penduduk yang berada di daerah bantaran Kali Harun, hal negatif yang dapat timbul akibat hal tersebut adalah dapat membuat pendangkalan Kali Harun karena kebiasaan buang sampah yang dilakukan para warganya dan dibuang langsung ke kali. Selain itu, keadaan tanah di sekitar kiri dan kanan bangunan bisa saja ambles dan menutup sisi-sisi kali. Hal tersebut menyebabkan penyempitan aliran kali dan rawan akan terjadinya banjir. Biasanya banjir akan timbul pada daerah-daerah yang memiliki kontur tanah yang rendah letakknya di dataran yang rendah. Hal tersebut sesuai dengan teori bahwa air akan mengalir dari tempat yang datarannya tinggi ke tempat yang datarannya lebih rendah. Kondisi tersebut memungkinkan terjadinya banjir akan lebih besar. Karena tingginya intensitas curah hujan, jika hujan lebat terjadi telah berlarut-larut dalam waktu yang lama akan sangat berpotensi terjadi banjir. Terutama pada daerah-daerah yang juga memiliki kontur tanah yang rendah.

Drainase merupakan salah satu infrastruktur yang penting bagi suatu kota dalam mencegah terjadinya banjir. drainase banyak diubah tanpa mengindahkan amdal. Hal tersebut banyak terjadi di daerah perkotaan. Daerah hutan atau rawa seharusnya juga dapat berguna untuk mengatasi banjir. Namun pada realitanya, banyak lahan yang telah dialih 
Peninggian Saluran Air Sebagai Solusi Mengurangi Banjir Di Perumahan Bukit Kencana, Bekasi, Jawa Barat

fungsi menjadi mall atau gedung-gedung perkantoran. Penyeimbangan antara pembangunan di daerah kota dan kawasan drainase kota sebaiknya perlu dilakukan agar dapat mencegah terjadinya banjir.

Kesalahan pada sistem tata kelola ruang di daerah perkotaan biasanya seringkali menyebabkan sering terjadinya banjir. Dengan adanya kesalahan tersebut, biasanya air akan sulit menyerap ke dalam tanah dan menyebabkan aliran air menjadi lambat. Sementara pada musim penghujan, air yang datang ke daerah tersebut akan lebih banyak jumlahnya dari biasanya sehingga dapat cepat menyebabkan banjir. Ketidakmampuan tanah dalam melakukan penyerapan air biasanya disebabkan karena berkurangnya lahan hijau atau lahan terbuka lainnya. hal tersebut mengakibatkan air masuk ke dalam saluran, kali, ataupun selokan. Apabila tempat-tempat tersebut sudah meluap, dapat dipastikan bahwa air yang meluap mengakibatkan banjir.

Bagi sebuah perkotaan, daerah resapan air merupakan suatu kunci untuk mencegah terjadinya banjir. Namun kebanyakan saat ini daerah resapan air di perkotaan telah beralih fungsi sebagai pemukiman warga. Akibatnya daerah resapan air akan semakin sedikit dan akan memicu potensi banjir lebih tinggi pada saat datangnya musim penghujan.

Irigasi adalah segala usaha manusia yang berhubungan dengan perencanaandan pembuatan sarana untuk menyalurkan serta membagi air ke bidang-bidang tanahpertanian secara teratur, serta membuang air kelebihan yang tidak diperlukan lagi.

Menurut Sa'ud (2007).Kawasan yang tergenang dari tahun ke tahun semakin meningkat. Hal ini menunjukkan bahwa kapasitas saluran pemutusan saat ini sudah tidak mampu lagi mengalirkan air limpasan yang semakin tahun semakin besar karena perubahan fungsi lahan. Kondisi seperti ini bertambah parah karena kesadaran masyarakat masih kurang untuk ikut bertanggung jawab terhadap keberadaan saluran pematusan.

Menurut Siswaadianta (2019), pengelolaan Aliran Air Permukaan (storm water management); yaitu pengelolaan aliran air hujan ke tempat penerima air; sungai atau alur aliran. Secara definisi, itu merupakan pengontrolan aliran air menuju sungai, dan bukan aliran pada sungai itu sendiri yang biasa disebut sebagai pengendalian banjir. Dengan demikian permasalahan drainase dan banjir dapat dikontrol langsung pada sumbernya dengan menggunakan prinsip "tidak ada penambahan aliran" dari keadaan sebelum pengembangan (pembangunan).

Masalah banjir berdampak sangat luas terhadap aspek kehidupan masyarakat.Oleh sebabitu kegiatan pembangunan hendaknya selalu mempertimbangkan berbagai aspek kehidupan, sehingga tidak menimbulkan dampak terjadinya banjir, dalam rangka meningkatkan kesejahteraan masyarakat. Perubahan lingkungan yang diakibatkan oleh berbagai kegiatan manusia,serta perubahan iklim, khususnya pemanasan global, berpengaruh sangat signifikan terhadap upaya mengatasi masalah banjir (Wicaksono, 
Peninggian Saluran Air Sebagai Solusi Mengurangi Banjir Di Perumahan Bukit Kencana, Bekasi, Jawa Barat

Saputra, Budieny, \& Kadir, 2013)

Menurut Kumalasari \& Tisnawati (2018) Selama ini penatagunaan drainase perkotaan lebih banyak direncanakan dan dikerjakan oleh pemerintah, sehingga pemerintah seringkali disalahkan apabila terjadi genangan yang mengganggu aktivitas masyarakat. Terlepas dari baiknya teknis perencanaan dan pengerjaan, seringkali kondisi sarana dan prasarana drainase perkotaan yang sudah ada cenderung terbengkalai dan tidak terjaga dengan baik oleh masyarakat karena tidak adanya rasa memiliki dan tanggung jawab dari masyarakat.

Penataan sistem drainase permukiman berbasis masyarakat ini perlu dilakukan agar masyarakat lebih aktif berperan serta dalam upaya pengendalian masalah banjir dan genangan dengan melaksanakan system informasi terpadu mulai tahap perencanaan, pelaksanaan konstruksi hingga penyelenggaraan operasional

Pemerintah Kota Bekasi, Jawa Barat, mengintensifkan penertiban terhadap sejumlah bangunan liar yang dianggap menjadi pemicu banjir di beberapa kawasan setempat. Pemerintah Kota Bekasi mengaku telah menyiapkan dari gabungan Satpol PP, TNI, Polri, Dinas Kebersihan, Bina Marga dan Tata Air, aparatur kecamatan setempat. Tim tersebut juga akan melakukan pembongkaran bangunan serta menguras saluran air untuk dinormalisasi dan lahan juga akan dikembalikan ke fungsinya sebagai saluran air.

Pembongkaran bangunan di atas saluran air ini dilaksanakan atas dasar :

- Peraturan Daerah Kota Bekasi Nomor 13 Tahun 2016 tentang Penyelenggaraan Izin Pemanfaatan Ruang.

- Peraturan Daerah Kota Bekasi Nomor 04 Tahun 2017 tentang Penyelenggraan Retribusi Izin Mendirikan Bangunan dan

- Peraturan Walikota Bekasi Nomor 24 Tahun 2014 tentang Garis Sempadan Sungai

Sehubungan dengan keberadaan bangunan yang terpantau berada di atas Kali Harun yang menghambat aliran air, yang berlokasi di Kaveling Amril RT.11-RW.08. No 110, Kelurahan Jati Makmur - kecamatan Pondok Gede Kota Bekasi Selatan 1741, adalah bangunan yang berada di atas saluran Kali Harun. Menindak lanjuti Surat Peringatan dari Kelurahan Jati Makmur sebagai berikut:

- Surat Peringatan I Nomor 474/261-KI Jmm, tanggal 01 November 2017

- Surat Peringatan II Nomor 474/280-KI Jmm, tanggal 15 November 2017

- Surat Peringatan III Nomor 474/280-KI Jmm, tanggal 04 Desember 2017

- Surat Undangan Rapat Koordinasi dari Pemerintah Kota Bekasi DINAS TATA RUANG Nomor : 005/335/ Distaru.tanggal 28 Februari 2020.

- Surat Perintah Bongkar dari Pemerintah Kota Bekasi DINAS TATA RUANG Nomor: 640/379/Distaru. Tangal 05 Maret 2020, (terlampir) berperihal perintah untuk segera membongkar sendiri bangunan / prsarana bangunan di atas saluran kali Harun tersebut.

Dari fenomena yang ada tersebut, penulis tertarik untuk menulis dan menuangkan sebagai Laporan Pengabdian kepada Masyarakat khususnya bagi masyarakat di Perumhanan Bukit Kencana TR.19 - RW .03 Kelurahan Jati Makmur Pondok Gede - Bekasi Jawa Barat, pada saat curah hujan tinggi mengalami banjir akibatnya sebanyak 237 rumah 
Peninggian Saluran Air Sebagai Solusi Mengurangi Banjir Di Perumahan Bukit Kencana, Bekasi, Jawa Barat

terendam banjir dengan variasi ketinggian $15 \mathrm{~cm}$ hingga $70 \mathrm{~cm}$ dimana penyebab utamanya adalah terhambatnya arus alran air menuhju ke hilir. Sebagai warga Negara yang baik tentu kami akan beritikat baik, koperative sesuai aturan ikut berpartisipasi dalam menggulangi banjir, kami membongkar dan meninggikan saluran air di bawah bangunan rumah agar tidak lagi menjadi penghambat jalanya air saat curah hujan tinggi.

\section{METODE}

Metode dalam Pengabdian Masyarakat ini menggunakan PAR (Participatory Action Research) dimana metode ini langsung pendekatan kepada masyarakat dengan melihat kondisi langsung dilapangan yang dilaksanakan secara partisipatif di masyarakat dalam suatu komunitas di tingkat RT dan RW. Kegiatan pengabdian ini dilakukan selama 1 bulan dimulai dari tanggal 01 April 2020 sampai dengan 30 April 2020. Kegiatan ini menggunakan tiga tahap yaitu tahap pertama melakukan survey dan observasi kondisi saluran drainase di daerah penelitian, yang menurut masyarakat sering terjadi luapan air ketika hujan turun dengan melibatkan warga dan didampingi oleh Dinas tata Ruang Kota Bekasi. Tahap keduan pemetaan lokasi dititik banjir di wilayah RT dan RW setempat. Tahap ketiga adalah tahap pelaksanaan yang dilakukan Bersama di komunitas di tingkat RT dan RW dengan disaksikan dan dibantu oleh pihak Dinas Tata Ruang Kota Bekasi.

\section{HASIL DAN PEMBAHASAN}

Saluran pencampur dibuat di jaringan utama sebagai saluran irigasi primer. Saluran drainase merupakan saluran air atau jalur pembuangan air untuk mengurangi kelebihan air. Saluran drainase direncanakan untuk menampung debit rencana dengan aman berdasarkan data curah hujan, tata guna lahan dan dimensi saluran. (Suharto, 2020)

Kegiatan awal yang dilakukan, yaitu berkoordinasi dengan kepala Kelurahan Jati Makmur, ketua RT.19, dan ketua RW.03 Perumahan Bukit Kencana sebagai pihak yang terkena dampak banjir akibat adanya penyempitan saluran air yang ada ketua RT.11-dan ketua RW.08, setelah melakukan diskusi untuk mencari kesepakatan, kemudian kegiatan Pengabdian Kepada Masyarakat melakukan koordinasi observasi dengan DISTARU Kota Bekasi atas kesediaan membantu pelaksanaan pekerjaan peninggian saluran air dengan menggunakan metode yang telah disepakati dan dengan biaya swadaya sendiri dengan kegiatan sebagai berikut.

Pembersihan dan pembongkaran/pembobokan area kerja, meliputi pekerjaan memindahkan perabotan rumah tangga ke lokasi aman dan membongkar/pembobokan lantai beton dengan menggunakan Jack humer, dan memotong besi behel nya dengan lampu potong acytilin (LPG\&Oxigen) 
- Pengukuran dan persiapan alat-alat kerja dan tenaga,

- Pemasangan dinding bibir kali 1 bata sepanjang 15 meter $\times 1$ meter $\times 2=$ luas 30 Meter

- Plesteran dan acian dinding bata 15 meter $\times 1$ meter $\times 4=60$ meter

- Pemasangan penguat baja ringan 15 meter $\times 2$ meter $=30$ meter

- Pemasangan landasan plat spandek cor beton 15 meter $\times 2$ meter $=30$ meter

- Perakitan pembesian warmes 15 meter $\times 2$ meter $=30$ meter

- Pemasangan cetakan/bekisting beton, panjang15 meter $\times$ lebar 2 mter $=30$ meter

- Pengecoran beton K 225, panjang 15 meter $x$ lebar 2 mter $x$ tinggi 0.10 meter $=3 \mathrm{M}^{3}$

- Pekerjaan finishing, mengaci, pengecatan, pembersihan dan dll

Kegiatan Pengabdian Kepada Masyarakat ini adalah Pekerjaan Peninggian Saluran Air dilokasi RT.08-RW.11, sebagai solusi mengurangi banjir di Perumahan Bukit Kencana RT.19RW.03-Kelurahan Jati Makmur - Kecamatan Pondok Gede - Kota Bekasi-Jawa Barat dengan jumlah warga sebanyak 237 jiwa, kegiatan ini memiliki dua opsi yaitu pertama membongkar semua bangunan dan membebaskan saluran air tanpa ada bangunan diatasnya, opsi kedua yaitu meninggikan saluran air sampai batas yang disepakati yaitu peninggian tanggul bibir kali 1,5 meter sepanjang 13 meter dan lebar 2,5 meter.krena di area rumah warga tersebut sudah ada bangunan lantai dua, dan instalasi air, listrik dan lain lainya.

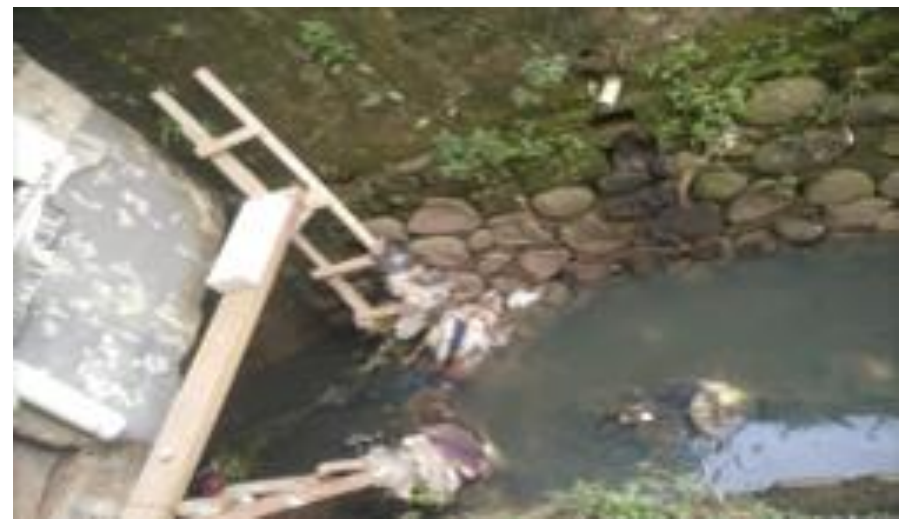

Gambar 1. Saluran Air Sebelum Peninggian

Kondisi bangunan sebelum dilakukan peninggian saluran air, jika hujan lebat, bangunan tersebut menjadi penghambat jalanya air karena air menabrak bangunan dan berbalik, menyebabkan banjir 


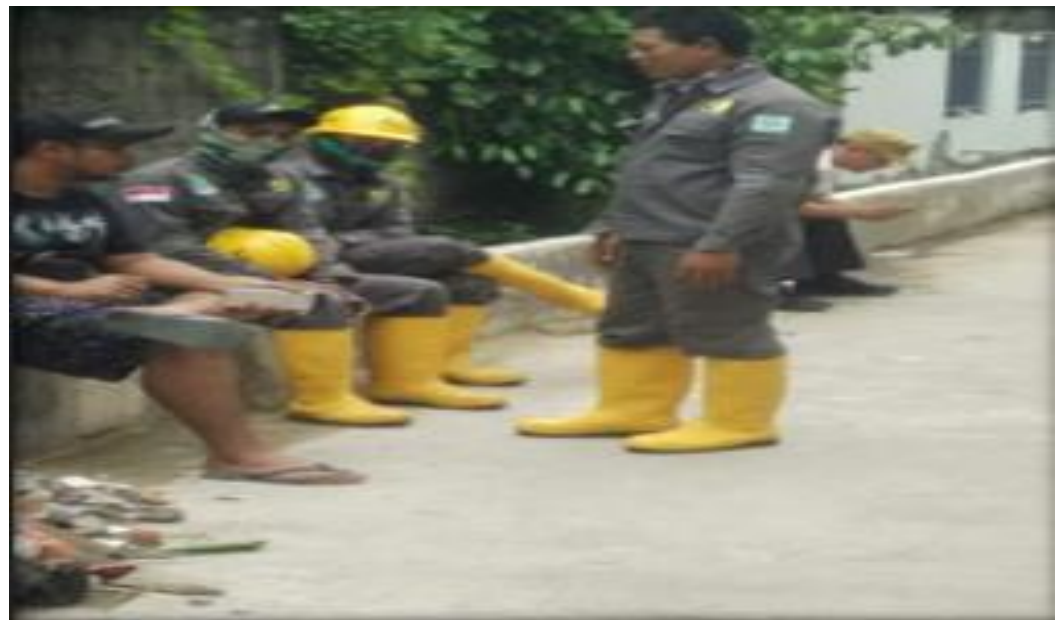

\section{Gambar 2. Personal dan Alat Kerja}

Personal dan alat kerja dari Dinas Tata Ruang (TARU) Kota Bekasi, yang membantu membongkar banguanan yang akan ditinggikan untuk memperlancar saluran air

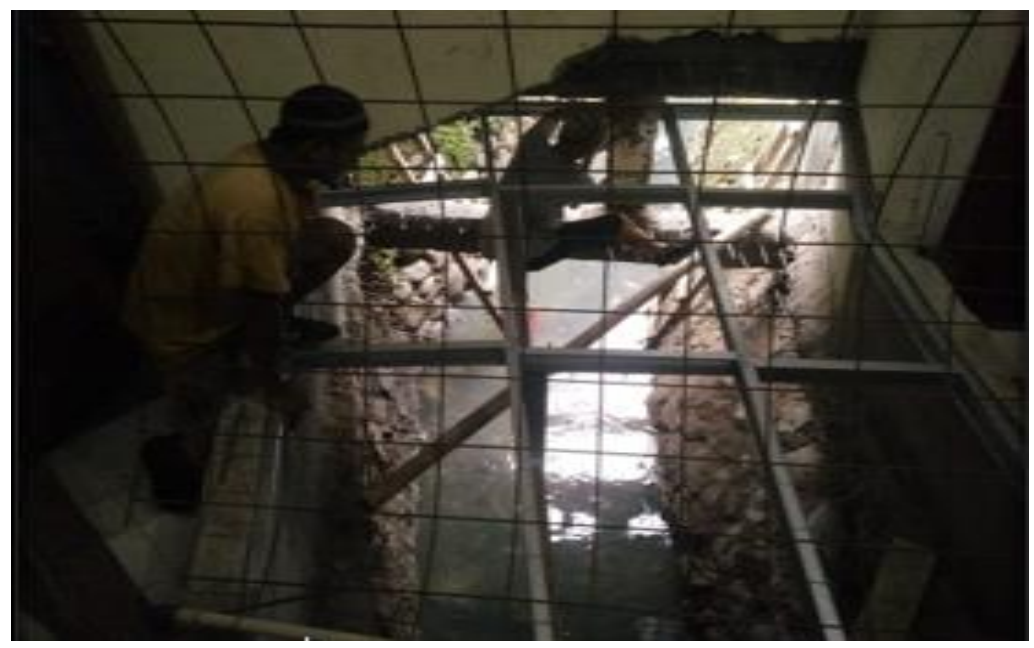

Gambar 3. Tenaga Kerja

Tenaga kerja tukang dan warga yang bekerja dengan hanya menggunakan alat konvensional, sehingga hasil pekerjaannya sangat lambat, hal ini menjadikan kekawatiran akan turun hujan, yang beresiko air masuk kerumah warga .

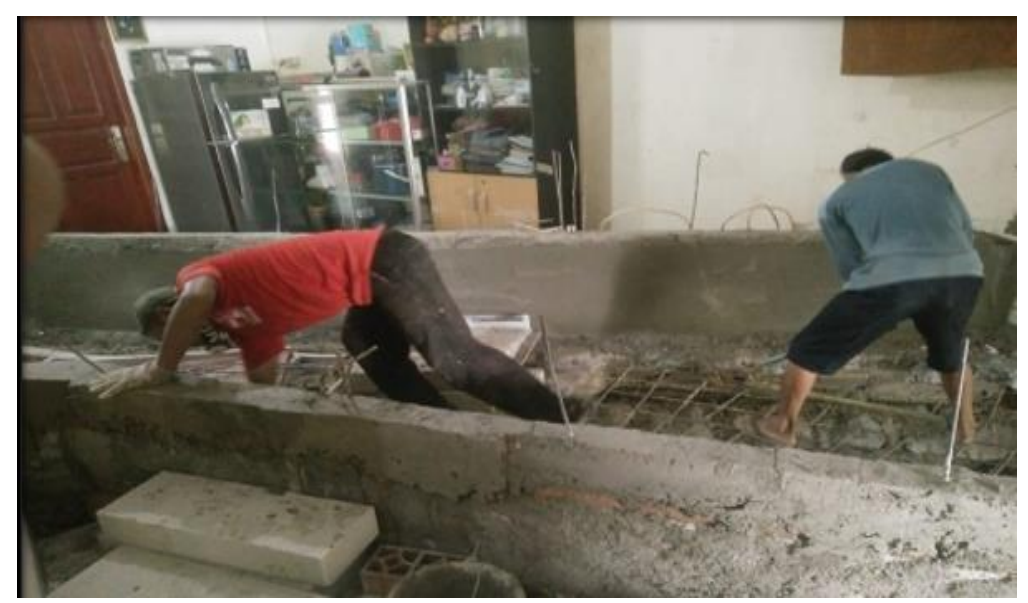

Gambar 4. Tenaga Kerja dengan Alat Konvensional 
Setelah banguan lama yang menghambat saluran air dibonkar, selanjutnya membuat peninggian dinding dari bibir kali setinggi $120 \mathrm{~cm}$, selanjutnya dindng itu nantinya akan dtutup kembali dengan cor.

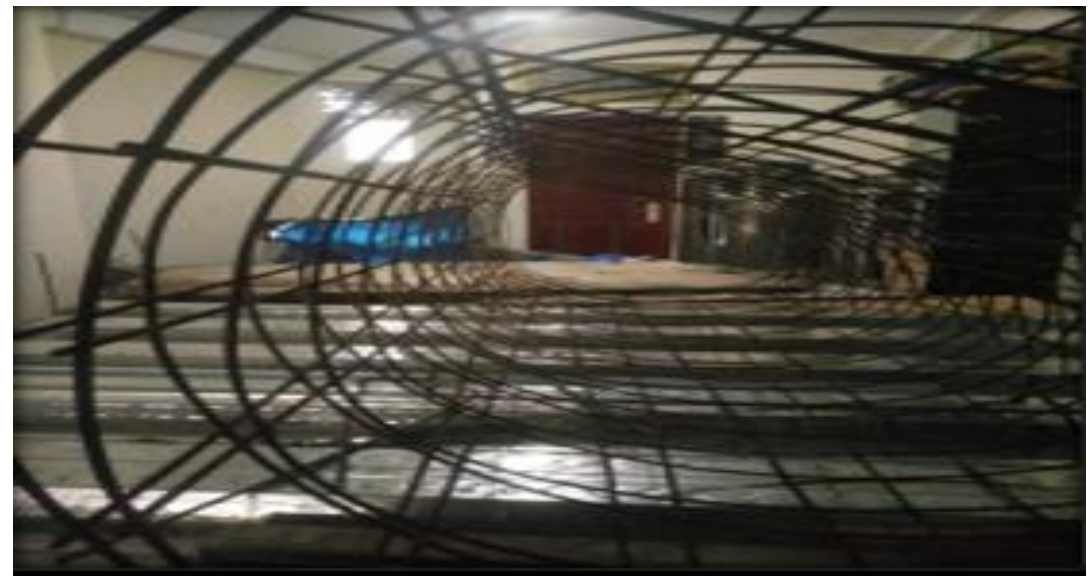

Gambar 5. Proses Perakitan Pembesian

Proses perakitan pembesian untuk menutup kembali bangunan yang sudah di bongkar dan ditinggikan, dengan cor menggunakan tulang besi wermes.

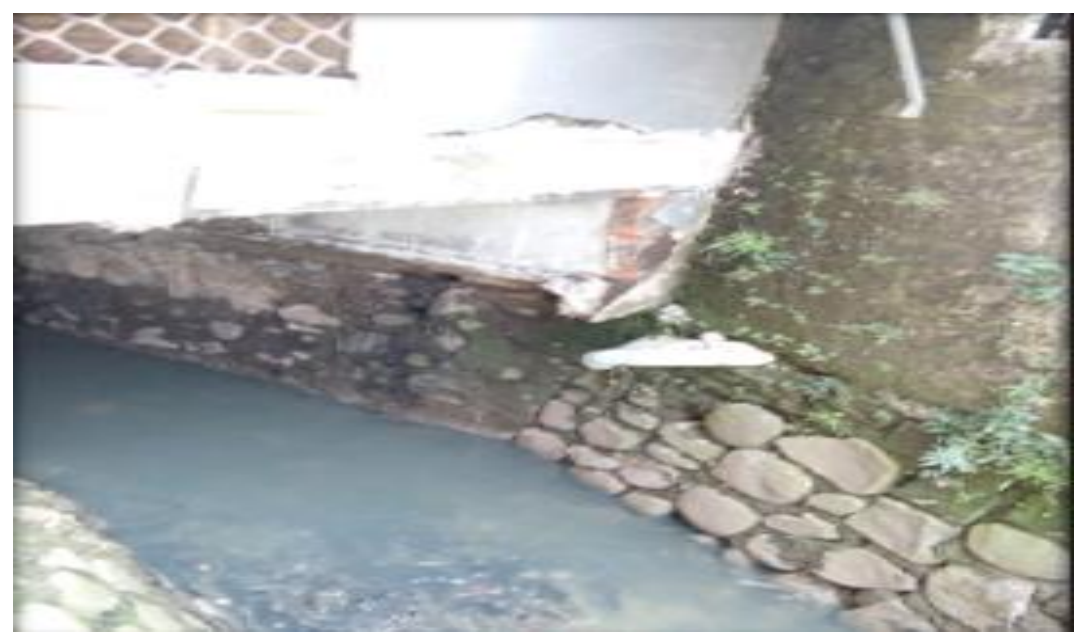

Gambar 6. Kondisi Peninggian Saluran Air

Kondisi bangunan seteah dilakukan peninggian saluran air, jika hujan lebat, bangunan tersebut tidak lagi menjadi penghambat jalanya air karena air tidak lagi menabrak bangunan dan air tidak berbalik, sehingga tidak menyebabkan banjir.

Dari beberapa gembar kegiatan pelaksanaan pengabdian masyarakat diatas maka selama proses pekerjaan peninggian saluran air ini dapat dilihat dari foto-foto kegiatan Pengabdian Kepada Masyarakat, tujuan utama kegiatan Pengabdian Kepada Masyarakat dan warga di Perumhanan Bukit Kencana TR.19 - RW .03 Kelurahan Jati Makmur untuk terbebas dari banjir saat curah hujan tinggi, serta dalam kegiatan agar berjalan lancar tanpa ada kesulitan, karena di dalam Pengabdian Kepada Masyarakat didukung semua warga serta peran serta Dinas Tata Ruang Kota Bekasi. Semua menyadari pentingnya dan kegunaan dari saluran air yang tidak menghambat aliran air, disamping tetap menjaga disiplin dari warga itu sendiri untuk 
membuang sampah pada tempatnya tidak membuang samapah ke kali, karena akan dampaknya selain mengakibatkan penyempitan badan kali dan menghambat aliran air juga berdampak ada kesehatan lingkungan sekitarnya.

\section{KESIMPULAN}

Kegiatan pengabdian masyarakat ini dengan membuat peninggian saluran air adalah Solusi agar sebanyak 237 rumah di Perumhanan Bukit Kencana TR.19 - RW .03 Kelurahan Jati Makmur pada saat curah hujan tinggi tidak lagi terendam banjir adalah dengan membangun dan meniggikan saluaran air.yang semula tinggi 2 meter menjadi 3,5 meter sepanjang 13,5 meter.

Teknik pelaksanaan kegiatan yang digunakan untuk peninggian saluran air yang berada di bawah bangunan rumah dengan ukuran tinggi 2,5 Meter selama \pm 10 tahun menjadi penghambat jalanya air dan penyebab banjir ketika curah hujan tinggi adalah dengan meniggikan saluaran air dan teknik yang digunakan adalah sebagai berikut.

- Pembersihan dan pembongkaran/pembobokan area kerja, meliputi pekerjaan memindahkan perabotan rumah tangga ke lokasi aman dan membongkar/pembobokan lantai beton dengan menggunakan Jack humer, dan memotong besi behel nya dengan lampu potong acytilin (LPG\&Oxigen) dengan ukuran panjang 13,5 meter $x$ lebar 2,5 meter $=33,75 \mathrm{M}^{2}$

- Pengukuran dan persiapan alat-alat kerja dan tenaga kerja,

- Pemasangan dinding bibir kali 1 bata sepanjang 13,5 meter $\times 1,5$ meter $\times 2=$ luas $40,5 \mathrm{M}^{2}$

- Plesteran dan acian dinding bata dari bibir kali panjang 13,5 meter $\times$ tinggi 1,5 meter $\times 4=81$ $\mathrm{M}^{2}$

- Pemasangan penguat baja ringan panjang 13,5 meter $x$ lebar 2,5 meter $=33,75 \mathrm{M}^{2}$

- Pemasangan landasan plat spandek cor beton panjang 13,5 meter x lebar 2,5 meter =33,75 $\mathrm{M}^{2}$

- Perakitan pembesian warmes panjang 13,5 meter $x$ lebar 2,5 meter $=33,75 \mathrm{M}^{2}$

- Pemasangan cetakan/bekisting beton, panjang13,5 meter $x$ lebar 2,5 meter $=33.75 \mathrm{M}^{2}$

- Pengecoran beton K 225, panjang 13,5 meter $x$ lebar 2,5 mter $x$ tinggi 0.10 meter $=3,375 \mathrm{M}^{3}$

- Pekerjaan finishing, mengaci, pengecatan, pembersihan dan lain-lain.

\section{DAFTAR PUSTAKA}

Desmawan, B. T., \& Sukamdi, S. (2012). Adaptasi masyarakat kawasan pesisir Terhadap banjir rob di kecamatan sayung, Kabupaten demak, jawa tengah. Jurnal Bumi Indonesia, 1(1).

Departemen Pekerjaan Umum. Undang-undang No 7 Tahun 2004. Sumberdaya Air. DinasPekerjaan Umum. Jakarta.

Khaerudin, D. N., \& Krisnayanti, D. S. (2014). Penerapan Saluran Pencampur Pada Sistem Irigasi Tambak. Jurnal Irigasi, 9(1), 41-50.

Kumalasari, D., \& Tisnawati, T. (2018). PENATAAN SISTEM DRAINASE PERMUKIMAN BERBASIS MASYARAKAT DENGAN METODE PERENCANAAN PARTISIPATIF DI KELURAHAN PONCOL KECAMATAN PEKALONGAN TIMUR. Pena Jurnal Ilmu Pengetahuan dan Teknologi, 32(1), 19-30.

Suharto, S. (2020). ANALISA KAPASITAS DIMENSI SALURAN DRAINASE DI JALAN KEBUN AGUNG SAMARINDA. Jurnal Kacapuri: Jurnal Keilmuan Teknik Sipil, 3(2), 122-134.

Setiabudi, B. (2009). PENCEGAHAN BANJIR, DAN PENURUNAN MUKA AIR TANAH 

DENGAN SUMUR RESAPAN. METANA, 6(01).

Sa'ud, I. (2007). Kajian Penanggulangan Banjir di Wilayah Pematusan Surabaya Barat. Jurnal Aplikasi Teknik Sipil, 3(1), 1-10.

Siswaadianta, D. (2019). Analisis Penanganan Banjir DAS Jatimulya (Studi Kasus: Perumahan Jatimulya, Bekasi). JURNAL TEKNIK SIPIL-ARSITEKTUR, 18(2), 68-77.

Wicaksono, A., Saputra, P. D., Budieny, H., \& Kadir, A. (2013). Perencanaan Sistem Drainase Pasar Johar Semarang. JURNAL KARYA TEKNIK SIPIL, 2(2), 31-38. 